\title{
JORNADA DE TRABALHO: uma regulamentação em múltipla escolha*
}

\section{Leila Maria da Silva Blass}

\author{
O controle sobre as horas extras "tem dois fundamentos: um deles é inverter a hora extra para criar emprego; e o outro, descansar. O pessoal usar \\ isso para folgar e não se matar na hora extra". \\ (Depoimento de um diretor sindical na Volkswagen)
}

\section{Introdução}

O tempo de trabalho constitui uma temática clássica dos estudos a respeito da organização capitalista do processo de trabalho, e a sua regulamentação, nas palavras de Dal Rosso (1996), seria a "espada que corta" as relações entre empresários e trabalhadores desde o século XIX. Na história sindical brasileira, são inúmeras as lutas operárias e sindicais que tematizam a jornada de trabalho. Nesse sentido, os metalúrgicos da região do $\mathrm{ABC}$ paulista não são exceção quando relacionam redução da jornada de trabalho, emprego e progresso técnico.

Os acordos recentemente estabelecidos na Ford e na Volkswagen reatualizam, portanto, uma das questões candentes no movimento operário. Esses trabalhadores, quando entrelaçam o mundo do trabalho e o do nãotrabalho nas suas inúmeras mobilizações sindicais, inseremse no debate internacional, que se intensifica nas últimas décadas, a respeito do sentido e lugar do trabalho assalariado no conjunto das suas atividades sociais.
Os acordos que regulamentam a jornada de trabalho na Ford e na Volkswagen, respectivamente, em setembro de 1995 e janeiro de 1996 relacionam-se com as experiências de lutas operárias e sindicais deflagradas no decorrer dos anos 80 na região do $\mathrm{ABC}$ paulista e resultam das negociações estabelecidas entre representantes patronais e sindicais logo após a dissolução da holding Autolatina.

A Autolatina forma-se em junho de 1987, com a junção das subsidiárias Ford e Volkswagen instaladas no Brasil e na Argentina. Apesar da relativa integração produtiva, essas empresas competem no lançamento de novos carros no mercado consumidor brasileiro, preservam a sua própria rede de revendedores e fornecedores e relacionam-se separadamente com os sindicatos e com o governo. Um dos maiores obstáculos ao funcionamento cotidiano da Autolatina encontra-se na formulação de procedimentos comuns válidos para as duas empresas, o que dificulta bastante a tomada de decisões, principalmente no que se refere ao atendimento das demandas dos trabalhadores. Nesse caso, fica evidente as diferentes origens históricas 
das empresas envolvidas. As relações da Ford com o sindicato sempre estiveram marcadas por uma certa intolerância, pois as negociações diretas com os representantes dos trabalhadores horistas são sempre priorizadas, como aponta Beynon (1995a). A Volkswagen, ao contrário, considera o sindicato um legítimo representante político dos trabalhadores e negocia com a comissão de trabalhadores, interlocutor válido dos funcionários, sem qualquer distinção entre horistas e mensalistas.

Com as medidas econômicas adotadas pelo governo Collor e a abertura do mercado às importações de veículos, a continuidade da Autolatina parece ameaçada. A situação agrava-se com os protocolos assinados no governo Itamar Franco que incentivam a produção dos chamados carros populares. 1 As vendas dos carros populares estouram a partir de 1994, ao passo que os médios e grandes, faixa de mercado controlada pela Ford, passam a concorrer com os carros importados. Segundo dados fornecidos pela Associação Nacional dos Fabricantes de Veículos Automotores (Anfavea), a participação dos carros populares nas vendas no mercado interno atinge, em 1994, 45,9\%; em 1995, 53,8\%, e em 1996, 56,3\%.

O fim da Autolatina implica, do lado da Ford, os lançamentos dos carros Fiesta, em abril de 1996, e Ka, em março de 1997, como parte do projeto Ford 2000, demarcando a reinserção da subsidiária brasileira nas estratégias globais da empresa. Do lado da Volkswagen, resulta no início da produção do modelo de carro chamado Gol AB9, na unidade Anchieta, situada no município de São Bernardo do Campo; na implantação de um consórcio modular na fábrica de caminhões, em Resende (RJ), e outro na fábrica de motores, em São Carlos (SP), além de mudanças na gestão da produção e do trabalho como, por exemplo, a nova estrutura salarial dos horistas 2 e os acordos sobre a jornada de trabalho.

A implantação da jornada de trabalho em múltipla escolha suscita não só um debate em torno da desregulamentação das relações de trabalho e do sistema brasileiro de relações industriais, mas também uma reflexão acerca do imaginário de que se trabalha pouco no Brasil. $\underline{3}$ Tendo o respaldo político das comissões de fábrica, a jornada de trabalho em múltipla escolha exemplifica a proposta sindical conhecida por "reestruturação ou modernização negociada", fonte geradora de muitas tensões e conflitos no interior do movimento operário e sindical brasileiro no decorrer da década de 90.

O alcance e a abrangência dos acordos firmados, não obstante os resultados altamente positivos apresentados, parecem limitados ao âmbito das indústrias automobilísticas e da base sindical dos metalúrgicos do $\mathrm{ABC}$ paulista. Por isso, devem ser avaliados tendo em vista as lutas operárias e sindicais protagonizadas por esses trabalhadores(as) nas últimas décadas.

\section{Das jornadas heróicas de 1978-80 à modernização negociada dos anos 90}

Muitos estudos já demonstraram, reiteradamente, o papel decisivo das jornadas heróicas de 1978-80, movidas basicamente por reivindicações salariais e pela melhoria das condições de trabalho, no alargamento dos direitos sociais e políticos na sociedade brasileira e na aglutinação das forças políticas contra o regime militar. Esse processo confunde-se com a formação do Partido dos Trabalhadores (PT), da Central Única dos Trabalhadores (CUT), e com a trajetória política de Luís Inácio Lula da Silva.

Os trabalhadores e trabalhadoras da região do $\mathrm{ABC}$ paulista emergem no cenário histórico nesse momento e centralizam mais uma vez as atenções quando decidem participar das Câmaras Setoriais, no início dos anos 90. Num primeiro momento, inovam pela ousadia de dizer não e por suas conquistas trabalhistas, apesar da repressão policial e das demissões. No decorrer dos anos 70, promovem inúmeras paralisações nos intramuros das empresas, "no pé das máquinas", vindo a ocupar, no final dessa década, as principais ruas, praças e locais públicos da cidade de São Bernardo, enfrentando, muitas vezes, corpo- 
a-corpo as perseguições policiais. Em 1992, diante das conseqüências advindas das políticas econômica, fiscal, cambial e industrial implementadas pelo governo Collor, quando muitas empresas ameaçam transferir-se para outras regiões do país ou da América Latina, os metalúrgicos do $\mathrm{ABC}$ redirecionam a prática sindical, assumindo a defesa pública da Câmara Setorial do Complexo Automotivo. Os seus resultados são contundentes no que se refere aos índices salariais e de emprego. 4

Diante do processo de reestruturação produtiva, cujos contornos ficam mais claros em meados dos anos 90, as comissões de fábrica 5 e os dirigentes sindicais procuram formular propostas alternativas para se contrapor aos seus efeitos, que se expressam no discurso em torno da "modernização ou reestruturação negociada". A regulamentação da jornada de trabalho ilustra essa proposta, que se insere nas tradições políticas e organizativas desses trabalhadores(as), especialmente na Ford e na Volkswagen.

A jornada de 40 horas semanais de trabalho, sem redução de salários, compõe o plano de lutas aprovado no I Congresso Nacional da CUT, realizado em 1984 na cidade de São Paulo. Na campanha salarial de 1985, os metalúrgicos da região do $\mathrm{ABC}$ paulista assumem efetivamente esta bandeira de luta, tentando fugir das reivindicações estritamente salariais. Importa ressaltar que a jornada de trabalho não era tematizada pelo movimento operário e sindical brasileiro desde 1935. Como lembra Dal Rosso (1996, pp. 236-238), "cinqüenta anos é tempo suficiente para gerar [...] uma cultura do trabalho, que cimenta a mentalidade não só das contratações de trabalho, como também dos próprios assalariados". A reivindicação da redução da jornada de trabalho, afirma o autor, deixa claro para os trabalhadores que "existe algo mais do que apenas trabalhar na vida" (Dal Rosso, 1996, p. 264).

A greve "Vaca Brava", deflagrada em 1985, suscita um conjunto de questões como, por exemplo, a liberdade de dispor do tempo, a vida fora da fábrica, a construção dos laços afetivos com a família e os filhos. A sua forma organizativa funda-se na surpresa. $A$ cada dia, tendo por base um conjunto de dados e informações sistematizadas em "mapas da cadeia produtiva", dirigentes e militantes sindicais decidem qual(is) a(s) empresa(s) que será(ão) paralisada(s) e em que momento. Tentam, assim, deixar os empresários sem rumo, quer dizer, sem saber "qual é a fábrica que ia parar, qual ia continuar", pois quando "uma pára, a outra começa e descontrola todo o sistema de produção; desorganiza tudo, porque a produção é em cadeia, uma vai produzindo em seqüência da outra [...]". Na Volkswagen, conta um entrevistado, "nós estávamos parados porque não tinha peças, mas nós não estávamos em greve. Quando começou a chegar peça, aí nós paramos". $\underline{6}$

No decorrer desse movimento grevista, são firmados alguns acordos isolados por empresa. Por isso é difícil avaliar seu alcance. As pequenas empresas do setor de autopeças reduzem, de imediato, a jornada semanal de trabalho para 40 horas. Outras negociam essa jornada de trabalho para vigorar no decorrer de um ano; e outras, ainda, definem a jornada semanal de 44 horas para vigorar no prazo de até três anos. ${ }^{7}$ A jornada semanal de 45 horas de trabalho, em vigor antes do movimento grevista, continua nas montadoras da região do $\mathrm{ABC}$ paulista. Convém lembrar que essa greve quebra com uma jornada semanal de 60 horas, ou seja, as 48 horas legalmente definidas "mais 12 horas extras" (Dal Rosso, 1996, p. 269).

A Vaca Brava, ao inaugurar outra forma de greve, problematiza a concepção tradicional de que uma greve, como ação coletiva, é sempre de "todo mundo junto". Esta experiência, ao contrário, combina ações pontuais e diferenciadas segundo as características das empresas ou de setores de uma mesma fábrica, porém articuladas a um objetivo comum. Ela rompe, portanto, com uma das tradições grevistas presentes no movimento operário e sindical desde meados do século XIX, suscitando a reflexão sobre aspectos importantes da ação sindical no contexto de um processo de reestruturação produtiva. Destacaria, nesse sentido, a atuação no conjunto da cadeia produtiva, relacionando o todo $\mathrm{e}$ as partes constituintes, e a redefinição das prioridades para essa ação sindical, passando-se a avaliar o peso de cada empresa na produção 
final de uma determinada mercadoria. Assim, os critérios quantitativos - tamanho definido pelo número de funcionários ou por sua produtividade — tornam-se relativos, ganhando cada vez maior importância os critérios qualitativos, ou seja, o que se produz e em que condições.

Diante das mudanças nas políticas de gestão da produção e do trabalho que se desenrolam no âmbito das empresas, a experiência nas Câmaras Setoriais é freqüentemente relembrada com o objetivo de viabilizar uma prática sindical propositiva que atenue os efeitos dessas mudanças sobre os trabalhadores(as). Em meados dos anos 90, os trabalhadores já tinham tido inúmeras oportunidades de demonstrar o grau de conhecimento acumulado sobre o funcionamento dos vários processos de trabalho. As montadoras decidem, nessa época, modificar o conceito de fábrica na produção dos novos carros. Os altos investimentos mobilizados por esses empreendimentos fazem com que os representantes patronais se mostrem mais dispostos ao diálogo, reconhecendo, inclusive, a legitimidade de antigas reivindicações operárias como, por exemplo, a redução da jornada semanal de trabalho. Nessa medida, os acordos sobre a jornada de trabalho e as negociações na Ford e na Volkswagen relacionam-se com as inúmeras mobilizações operárias e sindicais deflagradas no decorrer dos anos 80 , revelando, ao mesmo tempo, uma das dimensões da reestruturação produtiva no Brasil.

\section{O desenrolar das negociações na}

\section{Ford/Taboão e na Volkswagen/Anchieta}

A campanha sindical pela semana de 40 horas de trabalho intensifica-se no decorrer de 1995, quando as Câmaras Setoriais são desarticuladas, na vigência do Plano Real de Estabilização Econômica. Alguns setores produtivos e algumas empresas são mais diretamente atingidos, provocando uma onda de demissões. A Mercedes-Benz, por exemplo, anuncia a dispensa sumária de 1.150 funcionários, sem abrir qualquer possibilidade de negociação com a comissão de fábrica. A instalação da nova fábrica Ford em São Bernardo do Campo e a transferência da produção da linha de motores mil para a Volkswagen instalada em São Carlos acarretam a supressão de milhares de postos de trabalho. $\underline{8}$ Apesar da reação dos trabalhadores, a empresa responde às manifestações concedendo períodos sucessivos de férias coletivas.

A palavra de ordem em favor da jornada de 40 horas semanais de trabalho ganha, assim, as ruas e praças públicas, reaparecendo como um mecanismo para ampliação e/ou manutenção do nível de emprego.2 Este discurso não traz nenhuma novidade; a derrota da luta sindical pelas 35 horas na Alemanha, no final dos anos 70, teria bloqueado, "pelo menos temporariamente, a possibilidade de ajudar na diminuição do já alto e crescente nível de desemprego através da redução da jornada de trabalho [...] depois que os instrumentos convencionais da política conjuntural esgotaram sua eficácia, ou evidenciaram-se como politicamente inviáveis" (Offe,1989, p. 133).

O movimento sindical e operário, ao tematizar a jornada de trabalho, põe a descoberto as múltiplas regras jurídicas que a regulamentam no Brasil. $\mathrm{Na}$ Constituição promulgada em 1988, ela está prescrita em 44 horas semanais; as empresas que se encontram sob a jurisdição do Sindicato dos Metalúrgicos do ABC têm, desde janeiro de 1996, a jornada de trabalho regulamentada em 43 horas semanais; nas montadoras, ela gira em torno de 42 horas por semana, conforme o protocolo assinado em abril de 1995.

As jornadas de trabalho nas empresas automobilísticas européias são significativamente inferiores àquelas das montadoras brasileiras. Por exemplo, as jornadas de trabalho, a partir das convenções coletivas de 1990, variam, na Espanha, entre 37 e 40 horas semanais; na França, de 35 a 39 horas semanais; na Itália, entre 36 e 40 horas semanais; em Portugal, de 36 a 48 horas semanais; e na Alemanha, de 36 a 40 horas, sendo que na Volkswagen a jornada semanal foi definida, em 1994, em torno de 28 horas com redução salarial (Dal Rosso, 1996, p. 23; SMABC, 1995a, p. 8). 
No caso da Ford, "a questão do excedente de mão-de-obra" ganha outro sentido porque se relaciona com os ajustes da "velha" Ford aos projetos Fiesta e Ka. Para isso, a empresa propõe a demissão de 1.282 funcionários somente em São Bernardo do Campo e abre um programa de demissões voluntárias ao qual adere uma minoria formada por aposentados ou empregados prestes a aposentar-se. Em contrapartida à reação dos trabalhadores, a Ford ameaça-os com o lay off, apelidado por estes de "bolsão". No lay off, os funcionários excedentes ficariam fora da fábrica por alguns meses, quando passariam a receber salários gradativamente menores, ou seja, "[...] 80\% dos salários no primeiro mês; $70 \%$, no segundo; $60 \%$, no terceiro; e 50\% no quarto mês" (Tribuna Metalúrgica, 19/9/1995; O Estado de São Paulo, 23/9/1995). 10

O "bolsão", embora rejeitado por unanimidade na Ford/Taboão, é aceito na unidade Ipiranga, situada na cidade de São Paulo. Para superar o impasse, dirigentes e militantes sindicais propõem a implantação de um banco de horas que funcionaria conforme as flutuações da produção e as demandas de mercado. As negociações prolongam-se por alguns dias, até os representantes patronais aceitarem flexibilizar a jornada de trabalho e introduzir o banco de horas. A partir de então, a jornada variaria entre 38 e 44 horas semanais, sem redução salarial, tendo por base a jornada de 42 horas semanais que vigora nas montadoras. A empresa compromete-se a implementar um banco de horas, sem qualquer definição por escrito. O acordo é aprovado na assembléia dos trabalhadores da Ford/Taboão, realizada em outubro de 1995, e no final de novembro estende-se às unidades instaladas em Osasco, Taubaté e Ipiranga, com o objetivo de compatibilizar os procedimentos administrativos. 11

Com a flexibilização da jornada de trabalho, as empresas podem usufruir da sazonalidade na produção de carros ${ }^{12} \mathrm{e}$ compensar "os custos adicionais" decorrentes da redução da jornada de trabalho. O seu ardil reside justamente nesse ponto, na medida em que "a flexibilidade das relações de trabalho tem por significado a possibilidade de um uso mais intensivo da força de trabalho, que, de um lado, viabilize ganhos permanentes de produtividade e conseqüentes reduções de custo e que, de outro, propicie a maleabilidade do processo produtivo numa situação de mudanças abruptas, no nível e na composição da demanda" (Dedecca e Montagner, 1993, p. 602).

A redução articulada à jornada flexível de trabalho possibilitaria, na visão de alguns dirigentes e militantes sindicais, manter ou ampliar o nível de emprego. Para outros, a redução e a flexibilização da jornada semanal de trabalho não interferem diretamente no nível de emprego. Afirma um entrevistado na Ford que a flexibilidade "aumenta o potencial produtivo a ponto de não gerar nada de emprego e pode desativar mais postos de trabalho". A instituição de um banco de horas tenta frear essa tendência na medida em que o seu funcionamento, segundo um entrevistado, permite "acumular horas de tal forma que vai chegar um momento que a empresa, mesmo que temporariamente, tenha de admitir gente. Tem uma necessidade, ela queima o volume de horas anual e, chega lá na frente, vai precisar contratar [...] através do contrato temporário".13 Um entrevistado na Volkswagen compartilha dessa avaliação, lembrando que a redução da jornada por si só "não gera emprego de forma imediata. Tinha 600 pessoas sobrando que não voltaram para seus locais de trabalho". 14 Nesse contexto, torna-se importante a instituição de um banco de horas, como demonstra o acordo da Volkswagen. $\underline{15}$

O desenrolar das negociações nesta empresa segue por caminhos diversos dos trilhados pela Ford, embora ambas persigam os mesmos objetivos. Com a dissolução da Autolatina, dirigentes sindicais e comissões de fábrica reúnem-se com os representantes patronais para traçar um diagnóstico prospectivo da fábrica Anchieta. As negociações iniciam-se com o acordo já firmado na Scania de 40 horas semanais com flexibilização da jornada de trabalho e um protocolo de intenções assinado pela Ford (Tribuna Metalúrgica, 1/12/1995), o que, nas palavras de um entrevistado da Volkswagen, criava "um gancho". $\underline{16}$

A situação competitiva de cada empresa no mercado tem uma importância relativa quanto à abrangência do acordo. A Volkswagen comemorava em 1995 o seu terceiro recorde 
consecutivo na liderança das vendas no mercado brasileiro, ao contrário da Ford, que na ocasião registrava uma queda acentuada nas vendas mas mantinha os seus compromissos de fornecer os motores mil (cilindradas) para a Volkswagen (Gazeta Merfantil, 5/7/1995). Agora, ressalta um entrevistado desta empresa, "estava claro para nós que a redução da jornada, flexibilidade, [era] no momento em que tivesse alta produção, senão não sairiam nunca $[\ldots] " .17$ Contudo, as projeções de vendas para a Ford no segundo semestre de 1997 são promissoras, e mesmo assim o banco de horas nesta empresa foge aos moldes da Volkswagen, $\underline{18}$ que o institui formalmente, por escrito.

O acordo da jornada de trabalho para os horistas é regulamentado na Volkswagen em dezembro de 1995 e prescreve, ainda, reajustes salariais, a incorporação do descanso semanal remunerado, a participação nos lucros e resultados, reajustes nos preços dos serviços de alimentação e transporte etc.

A jornada de trabalho passa a variar de 36 horas (jornada em vigor na Alemanha) a 44 horas semanais (jornada definida pela Constituição brasileira de 1988), tendo por base uma jornada média de 42 horas, vigente na região sob a jurisdição do Sindicato dos Metalúrgicos de São Bernardo do Campo. Se os horistas trabalharem acima de 42 horas até 44 horas semanais, resultem elas de atividades individuais ou coletivas, ou os mensalistas acima de 40 até 44 horas na semana, o excedente de horas estará creditado no banco de horas de cada trabalhador. Se os horistas trabalharem abaixo de 36 horas e os mensalistas de 40 horas, as diferenças serão debitadas da conta de cada funcionário. As horas acima das 44 até 48 horas semanais, sejam elas trabalhadas nos domingos, feriados ou em dias de férias, serão pagas nos valores negociados para as horas extras, além de serem creditadas no banco de horas. Explica um entrevistado:

Por exemplo, faço 8 horas e o adicional é 50\%. Então, teria 12 horas. Eu recebo o adicional monetário de 4 horas e as oito vão pro banco. Isso aqui é complemento do acordo, objetivando conter as horas extras ou limitar [...] quando trabalho 44 coletivamente, acumulo horas coletivamente para abater na jornada. Quando trabalho individual, acumulo horas individuais. Eu posso discutir com a chefia no fim de ano: "Olha, trabalhei mais, trabalhei menos. O que sobrar acerto nas férias". Veja só, todo esse esquema limita as horas extras... Eu só posso receber em dinheiro de 16 a 20 horas por mês, dependendo do mês: se forem 4 semanas são 16 (horas); se forem 5 são 20 horas. 19

\section{Acordo na Volkswagen}

\section{Horas extras}

Adicional + banco de horas

Banco de horas + adicional

Banco de horas

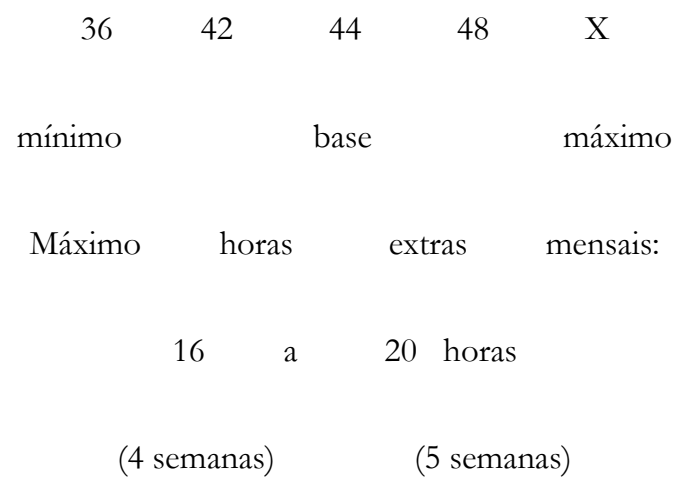

A Volkswagen é obrigada a divulgar amplamente, até o dia 23 de cada mês, a previsão da produção para o mês seguinte e da jornada para cada turno, porque os limites mensais das horas extras dependem desses cálculos. Segundo um gerente da empresa:

[...] na maioria dos meses nós temos mantido a jornada em 42 horas [...] Antes, quando se dizia "vou te pagar hora extra", ela era quase que imposta. Se o funcionário não viesse ele se sentia intimidado. Hoje em dia, não! Com o banco de horas, deu-se liberdade dele escolher: ele pode vir ou não [...] O acordo nos deixa engessados. Não é só vantagem para empresa. É vantagem para o sindicato e para o empregado também. $\underline{20}$ 
As folgas individuais ou coletivas, como as "pontes de feriado", podem ser usufruídas a qualquer momento, desde que consentidas pelos supervisores imediatos. Por exemplo, os dias entre o Natal e o Ano Novo, que totalizaram nove dias em 1996: quatro deles foram debitados do banco de horas (Tribuna Metalúrgica, 6/11/1996). Os atrasos, saídas antecipadas e as faltas injustificadas são debitados do banco de horas, e não descontados do descanso semanal remunerado ou das férias. O valor proporcional das horas excedentes está automaticamente incorporado aos salários mensais desde janeiro de 1996. Cada funcionário recebe, mensalmente, um holerite especial onde são registrados o total de horas trabalhadas, os adicionais e o saldo no banco de horas.

Os critérios para pagamento mensal, férias e $13^{\circ}$ salário dos horistas modificam-se com a redefinição da jornada de trabalho, uma vez que a base de cálculo se alterou. Os salários ficam desvinculados da jornada efetivamente cumprida em cada mês e os contratos de trabalho seguem regimes jurídicos diversos. A estruturação salarial dos horistas definida na época da Autolatina prepararia o terreno para a introdução da jornada flexível de trabalho, tanto na Ford quanto na Volkswagen, predefinindo os critérios de promoção da carreira. O acordo firmado na Volkswagen mostra-se, contudo, mais abrangente porque incide nos princípios da política salarial fordista, instituída no início do século XX, bem como nas relações de poder estabelecidas no interior da fábrica. Por exemplo, lembra um entrevistado, "o caso do domingo":

O cara que falta no meio da semana não perde o domingo, mas as horas. Antes não, perdia o domingo. $\mathrm{O}$ domingo agora está incorporado na tabela salarial. E o domingo era um instrumento de controle das pessoas. Descontando o domingo e feriado, o cara ia lá até morrendo... Acabou essa desgraça. .11

Os trabalhadores(as), particularmente na Volkswagen, reapropriam-se, assim, das horas extras, redefinindo a relação entre trabalho e salário. Para isso, superam as palavras de ordem "fim das horas extras", ou "semana de 40 horas semanais", ou "aumento no percentual de hora extra", fundadas na racionalidade homogeneizadora da organização fordista do trabalho. Propõem alternativas que se apóiam numa racionalidade diferenciadora, em que as preferências individuais são atendidas se forem obedecidas algumas regras.

A sua novidade repousa na criação de um banco de horas que, ao restringir a prática sistemática da hora extra, deixa evidente a dimensão pedagógica dessa normatização. $\mathrm{Na}$ opinião do atual coordenador da comissão de fábrica, "tem gente hoje na Volkswagen que faz 200 horas extras, com todo esse desemprego. Pra que? Pra receber dinheiro. E daqui a pouco ele vai fazer 200, mas vai receber 100 e [os outros] 100 vai ter que ficar parado na casa dele". No entanto, adverte ele, o desafio está no controle da flexibilização do tempo, porque "se deixar uma porta, pode descaracterizar até o sentido da flexibilidade. Hoje a gente sabe que a flexibilidade beneficia muito a firma, [então precisa] colocar alguma coisa que possa emperrar um pouquinho". $\underline{22}$

Os metalúrgicos da região do $\mathrm{ABC}$ paulista tentaram muitas vezes atacar "o diabo da extra", como define um entrevistado. Porém, observa ele:

Tem extras que são necessárias, essa a gente sabe. Mas como coibir a fábrica, parte da produção, com horas extras? [...] Muitos trabalhadores querem e "fazer o que?". O cara não entende o que é preservar a saúde, descansar, usufruir. Dependendo da situação do cara, ele vai ganhar um dinheiro e vai morrer ali trabalhando [...]. $\underline{23}$

A regulamentação da jornada de trabalho em múltipla escolha, desse ponto de vista, põe a descoberto os "fazedores de horas extras". Segundo um entrevistado:

[...] os mensalistas que fazem horas extras ficaram doidos da vida. Eles gostam de fazer hora extra; definiram os limites da sua vida livre em hora extra [...] Alguns chefes, poucos, chegaram até a boicotar esse negócio. Claro, é muito cômodo! O grosso da peãozada, os trabalhadores falaram: "olha, foi a melhor coisa que vocês fizeram, acumular no banco de horas". 24 
As horas extras têm legitimidade somente se forem necessárias para suprir as falhas no funcionamento dos processos de trabalho e/ou atender a demandas da produção devidamente justificadas pela empresa. Nesse aspecto, o banco de horas desempenha um papel fundamental porque "inibe tanto o trabalhador a fazer hora extra, quanto a empresa. Para a empresa, também não é muito interessante, de repente, num setor essencial como a manutenção, ter 20 pessoas [com] direito a ficar 10 dias em casa". .5 Por outro lado, complementa um diretor da Ford, a campanha do sindicato contra as horas extras e a sua defesa intransigente de mais emprego não impedem que os trabalhadores e seus representantes aceitem "completar as unidades, caso faltem componentes. Se tem mercado, as revendas estão pedindo, tem havido tolerância na base do voluntariado". $\underline{26}$

A jornada flexível de trabalho associada ao banco de horas funda-se, portanto, no princípio da co-responsabilidade, recolocando o debate sobre o estatuto político da liberdade e autonomia dos trabalhadores assalariados, como sugere Freyssenet (1992-93 e 1995). A relação capital e trabalho supõe, segundo esse autor, a "liberdade" de venda, por parte dos trabalhadores, das suas capacidades de trabalho e a dos capitalistas de comprá-las. Os parâmetros, embora preestabelecidos, são redefinidos e redimensionados conforme as exigências dos processos produtivos e a disponibilidade dos trabalhadores cujas necessidades são atendidas pela flexibilização da jornada de trabalho

As formas de controle sobre as horas excedentes, como sugere o depoimento inicialmente apresentado, seguem esse princípio: invertem a noção de hora extra e atribuem outro sentido e lugar ao trabalho assalariado. As heranças culturais, tradições políticas e várias experiências históricas influem nas decisões empresariais das multinacionais, expressando idéias e concepções emergentes nas sociedades de onde elas procedem. O debate contemporâneo, que se instala particularmente na Alemanha, sobre o lugar e o sentido do trabalho na vida individual e coletiva pode ilustrar esse fato. Embora não seja mencionado diretamente pelos entrevistados, as idéias a respeito do "tempo livre" e do direito ao trabalho, veiculadas pelo conselho de trabalhadores nas grandes indústrias e pelo movimento sindical alemão nos últimos anos, orientam as negociações que regulam a jornada de trabalho no Brasil, especialmente na Volkswagen.

Os acordos aqui analisados apresentam características diferentes, embora sejam semelhantes em seus objetivos. $\mathrm{Na}$ Ford, o acordo configura-se mais defensivo: a garantia do nível de emprego centraliza todas as atenções. $\mathrm{Na}$ Volkswagen, mostra-se mais ofensivo, na medida em que predefine e intervém nas normas contratuais de trabalho, garantindo os níveis salariais. Nessa medida, ambos questionam a visão empresarial que reivindica a redução da jornada de trabalho e dos salários. Quando o acordo na Volkswagen normatiza a previsão mensal da produção, permite o acesso, por parte dos trabalhadores e seus representantes, a informações que até então eram mantidas em sigilo. $\mathrm{O}$ sindicato e as comissões de fábrica passam a poder exigir, por cláusula estatutária acordada em 1985 (Bresciani e Oda, 1995, p. 48), informações sobre a introdução de inovações tecnológicas e organizacionais e, anos mais tarde, sobre o processo de terceirização (SMABC, 1995b, p. 33), uma das dimensões do processo de reestruturação produtiva. O funcionamento do banco de horas obriga a empresa a adotar uma prática de transparência administrativa e de planejamento, pois divulga amplamente e com antecedência as suas metas de produção.

\section{Considerações finais}

Foge aos objetivos deste artigo verificar em que medida a regulamentação da jornada de trabalho em múltipla escolha se insere na proposta de flexibilização das relações de trabalho na sociedade brasileira. No entanto, caberia assinalar que a mistura e justaposição de práticas e contratualidades, um dos traços marcantes do sistema brasileiro de relações industriais, estabelecem uma significativa margem de flexibilidade nas relações de trabalho nessa sociedade. 
Os acordos sobre a jornada de trabalho demonstram, portanto, uma certa vitalidade do movimento operário e sindical na região do $\mathrm{ABC}$ paulista, tendo em vista a situação do sindicalismo brasileiro em outras localidades, bem como as tendências internacionais. Os desdobramentos do acordo na Volkswagen deveriam ser avaliados, portanto, à luz das experiências de lutas desencadeadas na sociedade brasileira desde o final dos anos 70. Embora os acordos aqui tematizados não tenham sido precedidos por greves, isto não quer dizer, como sugere Dal Rosso (1996, pp. 218-219), um "reforço da flexibilização unilateral ou compulsória" onde prevaleceria "uma práxis social de acumulação de capital em outras bases". Os múltiplos aspectos envolvidos na regulamentação da jornada de trabalho indicam, contudo, quem são os seus atores sociais.

As lutas operárias e sindicais na região do ABC paulista, particularmente na Ford/Taboão e na Volkswagen/Anchieta, desempenharam um papel político importante na transição democrática brasileira. Mas fizeram-no reatualizando a prática das negociações diretas entre empresa, sindicato e trabalhadores, bastante difundida no interior do movimento operário e sindical de São Paulo no final dos anos 20 (Blass, 1986). Apesar dos resultados positivos para os trabalhadores, a sua abrangência está circunscrita aos muros dessas empresas. Nesse ponto reside uma das ambigüidades da proposta de "modernização negociada" formulada e veiculada pelos dirigentes sindicais dessa região.

Tendo em vista essas considerações, parece muito difícil enquadrar os acordos sobre a jornada de trabalho aqui analisados nas tendências gerais do uso flexível da força de trabalho no contexto do processo de reestruturação produtiva, como insistem alguns autores. Em muitos países, a redução da jornada de trabalho implicou uma correpondente redução salarial e muitos acordos firmados levaram à flexibilidade social extra-empresa, como sugere Salerno (1995a, p. 63). Na sociedade brasileira, o grande número de regras norteadoras dos contratos de trabalho já torna, paradoxalmente, o mercado de trabalho bastante flexível. Por isso Camargo (1996) questiona se essa tendência de flexibilização das relações de trabalho ocorre também no Brasil.

A empresa como o locus privilegiado e gerador de novas relações de trabalho também configura-se como uma das tendências contemporâneas do sistema de relações industriais, provocando a pulverização dos sindicatos e o afastamento do Estado das suas funções de regulação social. No Brasil, a regulamentação das relações de trabalho tem passado pelo interior das empresas, demonstrando a força política de alguns sindicatos, que acabaria por reforçar a privatização das relações de trabalho, uma das tradições da política brasileira. Desse modo, os acordos continuam correndo ao largo do Estado, não se estendendo à sociedade. $O$ que aparecia como força política se transformaria, alguns anos mais tarde, em fragilidade.

A introdução de novas formas de gestão da produção e do trabalho não persegue, portanto, um modelo único a partir do qual se explicaria o processo de reestruturação produtiva. As empresas transnacionais, adaptando-se às condições sociais e históricas delimitadas em fronteiras nacionais, tentam potencializar as vantagens que lhes são oferecidas. Nesse movimento, as múltiplas faces que compõem esse processo são reinventadas dentro das alternativas possíveis. Assim, "aquilo que parece mera imitação se torna, na verdade, recriação" (Castro, 1995, p. 18).

Os acordos sobre a regulamentação da jornada de trabalho mostram, do ponto de vista dos investimentos internacionais, o lugar das indústrias automobilísticas no projeto de modernização da sociedade brasileira nos anos 90. Do ponto de vista dos trabalhadores, esses acordos indicam um redirecionamento da prática sindical dos metalúrgicos do ABC paulista e expressam uma mudança de valores e de atitude diante do emprego. A instituição do banco de horas na Volkswagen e a desvinculação das horas extras dos salários reintroduzem o debate em torno do estatuto político da liberdade e autonomia no que se refere ao uso da força de trabalho pelo capital, pois cabe aos trabalhadores(as) decidir, a partir de então, quando e como usufruir das horas excedentes acumuladas durante um certo 
período. Nessa medida, eu ousaria afirmar que "os novos arranjos da jornada de trabalho são incentivados nem tanto como instrumentos para a superação do problema ocupacional, mas, pelo contrário, se baseiam em novas preferências quanto ao tempo de trabalho [...]" (Offe, 1989, p. 139).

A redução da jornada de trabalho não se relaciona apenas com a temática do emprego, mas suscita uma reflexão mais abrangente na qual se incluiria a questão da reapropriação e controle, por parte de quem vende força de trabalho, dos tempos destinados ao trabalho pago e ao trabalho não pago.

\section{NOTAS}

1 O carro popular define-se pela cilindrada e pelo índice de nacionalização das suas peças.

2 Nos últimos meses da Autolatina foi criado um plano de cargos e salários para os horistas, denominado tabela ou grade, composto de cinco graus diferenciados de funções (antes eram dez) e até sete níveis salariais. A progressão salarial é por mérito, mediante avaliação sistemática e individual do desempenho, escolaridade, participação em cursos de treinamento e reciclagem profissional. Cf. SMABC e Comissões de Fábrica dos Trabalhadores na Ford do Brasil (1995, p. 34) e Bresciani e Oda (1995, p. 48).

3 Quando se compara o total de horas trabalhadas no Brasil e em outros países, fica evidente a situação desvantajosa em que se encontram os trabalhadores brasileiros: numa jornada de 40 horas semanais, o total anual de horas trabalhadas seria de 1.838 horas e 34 minutos; numa jornada de 44 horas por semana, o total chegaria a 2.002 horas e 25 minutos. Em 1989, esse total perfazia, na Volkswagen, 1.443 horas e, na Ford (Inglaterra),1.673 horas. Ver SMABC (1995a, p. 33).

4 Os postos de trabalho diminuem 14,2\% entre 1990 e 1991, 8\% em 1991-92, 2,3\% em 1992-93, e 1,5\% em 1993 -
94, conforme a Tribuna Metalúrgica, 1/12/1994. Consultar também Arbix (1996a) e Salerno (1995a).

5 A comissão de fábrica da Ford/Taboão é regida por estatuto e regimento interno desde 1981. A da Volkswagen surge, inicialmente, como uma proposta patronal de representação interna dos trabalhadores, logo após a greve metalúrgica de 1980, que durou 41 dias. A proposta foi rejeitada em plebiscito interno realizado pelos empregados, que negociaram a eleição de comissões de fábrica por voto direto dos trabalhadores em todas as unidades da empresa no Brasil.

$\underline{6}$ Entrevistas realizadas por mim entre fevereiro e abril de 1989 com representantes das comissões de fábrica das montadoras e militantes sindicais metalúrgicos de Diadema.

7 Segundo o Departamento Jurídico do Sindicato dos Metalúrgicos do ABC, 76.394 de um total de 110.721 metalúrgicos retornaram ao trabalho depois de 54 dias de greve respaldados por acordos negociados diretamente com as empresas ou com o Sindipeças.

$\underline{\text { Em março de }} 1995$ havia, aproximadamente, 8 mil funcionários na unidade Taboão; em março de 1997 eram 5.500 .

9 Apesar do discurso sindical, o "efeito emprego é sempre inferior proporcionalmente ao nível de redução do trabalho devido às medidas implementadas pelas empresas de intensificação do processo de trabalho". Ver Dal Rosso (1996, p. 343).

$10 \mathrm{O}$ gerente de relações trabalhistas da Ford chama essa proposta de "licença parcialmente remunerada". Ver SMABC (1995a, p. 5).

11 Os trabalhadores da Ford/Taboão rejeitaram o limite máximo de 45 horas na flexibilização da jornada de trabalho em assembléia realizada em junho de 1996. Nas outras unidades Ford, a $45^{\mathrm{a}}$ hora trabalhada é, contudo, creditada no banco de horas. 
12 A flutuação da demanda varia no decorrer do ano. Os meses de março e abril são de baixa produção; entre maio e julho a produção começa a aquecer, atingindo o pico em outubro e novembro. Cf. SMABC (1995a, p. 32).

13 Entrevistas realizadas pela autora em 10 de agosto e 11 de dezembro de 1995.

14 Entrevista realizada pela autora em 6 de março de 1996. Ver também Folba de S. Paulo, 25/6/1997.

15 Em junho de 1995 a Volkswagen contratou 900 funcionários: 550 ficaram na Anchieta e 350 foram para Taubaté. Para o diretor de recursos humanos e o presidente do Sindicato dos Metalúrugicos do ABC, essas contratações resultaram do "acordo de flexibilização da jornada de trabalho e controle de horas extras, em vigor desde janeiro de 1996". Cf. Gazeta Mercantile Folha de S. Paulo, 25/6/1997.

16 Entrevista realizada pela autora em 7 de dezembro de 1995.

17 Entrevista realizada pela autora em 11 de dezembro de 1995.

$18 \mathrm{Na}$ Ford, o banco de horas foi firmado com base na "palavra", conforme entrevista realizada pela autora em 10 de março de 1997.

19 Entrevista realizada pela autora em 6 de março de 1996.

20 Entrevista realizada pela autora em 11 de outubro de 1996.

21 Entrevista realizada pela autora em 6 de março de 1996.

22 Entrevista realizada pela autora em 7 de dezembro de 1995.

23 Entrevista realizada pela autora em 6 de março de 1996.

24 Entrevista realizada pela autora em 6 de março de 1996.
25 Entrevista realizada pela autora em 7 de dezembro de 1995.

26 Entrevista realizada pela autora em 10 de março de 1997.

\section{BIBLIOGRAFIA}

ARBIX, Glauco. (1996a), Uma aposta no futuro. Os primeiros anos da câmara setorial da indústria automobilística. São Paulo, Scritta.

(1996b), "Trabalho: dois modelos de flexibilização". Lua Nova, 37:171-190.

BEYNON, Huw. (1995a), Trabalhando para a Ford. Trabalhadores e sindicalistas na indústria automobilística. Tradução de Laura Teixeira Motta. Rio de Janeiro, Paz e Terra.

- (1995b), "A destruição da classe operária inglesa?". Revista Brasileira de Ciências Sociais, 27, 10:5-27.

BLASS, Leila. (1986), Imprimindo a própria história: o movimento dos trabalhadores gráficos de São Paulo no final dos anos 20. São Paulo, Loyola.

- (1996a), Os metalúrgicos de São Bernardo na virada da história: da greve Vaca Brava em 1985 à noite de vigília contra a recessão em dezembro de 1991. Relatório final do CEPE/PUC-SP.

(1996b), A indústria do automóvel no Brasil e em Portugal no contexto da globalização. Relatório parcial FAPESP, no 1995/0155-4.

- (1996c), Los trabajadores y los cambios en la industria automotriz en Brasil. Trabalho apresentado ao VIII Seminário Internacional de Sociologia do RC 10 ISA, Santiago do Chile, datilo.

(1996d), Estratégias globais de relações industriais? Algumas reflexões sobre os acordos 
trabalhistas recentes na Ford e Volkswagen. Trabalho apresentado ao IV Congresso Luso-Afro-Brasileiro de Ciências Sociais, Rio de Janeiro, datilo.

(1997), A indústria do automóvel no Brasil e em Portugal no contexto da globalização. Relatório final FAPESP, no 1995/0155-4.

BRESCIANI, Luís Paulo. (1994), Da resistência à contratação. Tecnologia, trabalho e ação sindical no Brasil.Brasília, SESI-DN.

BRESCIANI, Luís Paulo e ODA, Nilson. (1995), Inovação tecnológica, mudança organizacional e negociação coletiva: o panorama brasileiro e o caso do complexo automotivo no ABC. São Paulo, $\mathrm{CNI} / \mathrm{SESI}$.

CAMARGO, José M. (1996), "Flexibilidade e produtividade do mercado de trabalho brasileiro", in J.Camargo (org.),Flexibilidade e mercado de trabalbo no Brasil, Rio de Janeiro, Ed. da Fundação Getúlio Vargas.

CASTRO, Nadya. (1995), "Modernização e trabalho no complexo automotivo brasileiro", in N.Castro (org.), A máquina e o equilibrista: inovações na indústria automobilística brasileira, Rio de Janeiro, Paz e Terra.

COMIN, Álvaro e CARDOSO, Adalberto. (1995), "Câmaras setoriais, modernização produtiva e democratização das relações de trabalho no Brasil: a experiência do setor automobilístico", in N.Castro (org.), $A$ máquina e o equilibrista: inovações na indústria automobilística brasileira, Rio de Janeiro, Paz e Terra.

DAL ROSSO, Sadi. (1996), A jornada de trabalho na sociedade: o castigo de Prometeu. São Paulo, LTR.

DEDECCA, Claudio e MONTAGNER, Paula. (1993), "Flexibilidade produtiva e das relações de trabalho. Considerações sobre o caso brasileiro". Anais do III Encontro Nacional de Estudos do Trabalho, Rio de Janeiro, ABET, vol. II: 597-617.
FREYSSENET, M. (1992-93), "L'invention du travail". Futur antérieur, 16:17-26.

(1995), "Historicité et centralité du travail", in J. Bidet e J. Texier (orgs.), La crise du travail, Paris, PUF.

OFFE, Claus. (1989), Trabalho \& sociedade. Problemas estruturais e perspectivas para o futuro da sociedade do trabalho. Tradução de Gustavo Bayer. Rio de Janeiro, Tempo Brasileiro.

RODRIGUES, Iram. (1990), Comissão de fábrica e trabalhadores na indústria. São Paulo/Rio de Janeiro, Cortez/Fase.

SADER, Eder. (1988), Quando novos personagens entraram em cena. Experiências, falas e lutas dos trabalhadores da Grande São Paulo (1970-80). Rio de Janeiro, Paz e Terra.

SALERNO, Mário. (1995a), "Flexibilidade e organização produtiva", in N. Castro (org.), A máquina e o equilibrista: inovações na indústria automobilística brasileira, Rio de Janeiro, Paz e Terra.

(1995b), "A trajetória história e as perspectivas de desenvolvimento da Autolatina no Brasil", inN.Castro (org.), A máquina e o equilibrista: inovações na indústria automobilística brasileira, Rio de Janeiro, Paz e Terra.

SILVA, Silvio César. (1996), As comissões de fábrica da Ford e da Volkswagen durante a Autolatina: práticas e experiências. Tese de mestrado, São Paulo, PUC-SP.

WOMACK, J.P., JONES, D.T. e ROOS, D. (1992), A máquina que mudou o mundo. Tradução de Ivo Korytowski. Rio de Janeiro, Campus. 


\section{Documentos consultados}

- Anfavea. (1995, 1996), Anuários estatísticos da indústria automobilística brasileira.

- Acordo coletivo de redução e flexibilização da jornada de trabalho na Volkswagen.

- SMABC — Sindicato dos Metalúrgicos do ABC. (1994), Qualidade de vida no trabalho na Mercedes-Benz do Brasil: as propostas dos trabalhadores.

- SMABC — Sindicato dos Metalúrgicos do ABC. (1995a), Redução da jornada de trabalho, limite de hora extra e reorganização do tempo de trabalho: as propostas alternativas dos metalúrgicos do ABC.

- SMABC — Sindicato dos Metalúrgicos do ABC. (1995b), Rumos do $\mathrm{ABC}$ : a economia do Grande $\mathrm{ABC}$ na visão dos metalúrgicos.

- SMABC - Sindicato dos Metalúrgicos do ABC/Comissões de fábrica dos trabalhadores na Ford do Brasil. (1995), Nova estrutura salarial horista.

- Subseção DIEESE. (1995), Indústria automobilística brasileira: informações gerais.

- Subseção DIEESE. (1987), "Autolatina: união contra quem?". Trocando em miúdos, 3.

· Fábrica S.B.C. em direção à Ford 2000.

- Autolatina, comunicado aos empregados. São Paulo, $1 / 12 / 1994$.

- Projeto FORD 2000. Estratégia da fábrica para liderança de mercado.

- SMABC - Sindicato dos Metalúrgicos do ABC/Subseção DIEESE. (1995), Política industrial, reestruturação produtiva e organização do trabalho.
- SMABC - Sindicato dos Metalúrgicos do ABC/Subseção DIEESE. (1996), Globalização e o setor automotivo. A visão dos trabalhadores da empresa.

*Este artigo faz parte do estudo comparativo, recentemente concluído, $A$ indústria do automóvel no Brasil e em Portugal no contexto da globalização, que teve apoio da FAPESP e do CNPq, no Brasil, e da JNICT, em Portugal. A análise da regulamentação da jornada de trabalho trata apenas das montadoras brasileiras que, até março de 1995, formavam a Autolatina. 